The Open Microbiology Journal
CrossMark

\title{
Isolation, Detection, and Characterization of Enterotoxigenic Bacteroides fragilis in Clinical Samples
}

\author{
Payam Fathi and Shaoguang $\mathrm{Wu}^{*}$ \\ Department of Medicine, Division of Infectious Disease, Johns Hopkins University, Baltimore, MD, USA
}

\begin{abstract}
Bacteroides fragilis is an extensively studied anaerobic bacterium comprising the normal flora of the human gut. $B$. fragilis is known to be one of the most commonly isolated species from clinical samples and has been shown to cause a wide range of pathologies in humans [1,2]. As an opportunistic pathogen B. fragilis can cause abscess formation and bacteremia [2]. Additionally in its enterotoxigenic form, B. fragilis is a known cause of diarrheal illness, is associated with inflammatory bowel disease, and has been recently characterized in patients with colon cancer [3 - 5]. As research in the field of the gut microbiome continues to expand at an ever increasing rate due to advances in the availability of next generation sequencing and analysis tools it is important to outline various molecular methods that can be employed in quickly detecting and isolating relevant strains of $B$. fragilis. This review outlines methods that are routinely employed in the isolation and detection of $B$. fragilis, with an emphasis on characterizing enterotoxigenic B. fragilis (ETBF) strains.
\end{abstract}

Keywords: Bacteroides fragilis, diarrheal illness, enterotoxigenicm form, human gut, non-enterotoxigenic.

\section{INTRODUCTION}

\section{B. fragilis and ETBF}

B. fragilis is a gram-negative, bile resistant, rod shaped member of the Bacteroidetes phylum and Bacteroides genus. It is referred to as a member of the B. fragilis group, which is used to describe species of Bacteroides based on phylogenetic similarities [6 - 8]. B. fragilis is described as being present in two different variations: Nonenterotoxigenic (NTBF) and Enterotoxigenic (ETBF) [7, 9]. Non-enterotoxigenic B. fragilis are characterized as symbiotic opportunistic pathogens assisting with polysaccharide metabolism and activating protective host immune responses [10]. The enterotoxigenic form of $B$. fragilis (ETBF) results from $B$. fragilis strains which contain the $B$. fragilis toxin (BFT) encoded by a gene ( $b f t$ ) located in a $6 \mathrm{~kb}$ pathogenicity island termed BfPAI along with an $18 \mathrm{~kb}$ flanking DNA region [11]. BFT, also called fragilysin, is a zinc-metalloprotease transcribed as a 397 amino acid protein holotoxin with an 18 amino acid signal sequence, a 193 amino acid propetide sequence, and a 186 toxin peptide sequence. Following cleavage of the signal and propeptide domains, biologically active BFT is $20 \mathrm{kDa}$ in size [12]. The toxin has been shown to be present in three different isotypes with varying toxicity: BFT-1, BFT-2, and BFT-3. BFT-2 is more toxic than BFT-1 or BFT-3 [13, 14]. BFT induces toxin activity by binding to a specific, as of yet uncharacterized, receptor on the surface of intestinal epithelial cells [15]. Following binding BFT results in the rapid cleavage of the E- cadherin protein in an ATP dependent fashion resulting in decreased barrier function and subsequent permeability of the epithelial cell barrier [16]. Downstream effects of the cleavage of E-cadherin include the induction of $\beta$-catenin signaling pathways which causes an increase in intestinal epithelial cell proliferation. Furthermore BFT toxin binding has been shown to also activate NF- $\kappa \mathrm{B}$ signaling pathways $[14,17]$.

\footnotetext{
* Address correspondence to this author at the Department of Medicine, Division of Infectious Disease, Johns Hopkins University School of Medicine, Baltimore, MD, 21231, USA; E-mail: sgwu@jhmi.edu
} 


\section{Role in Gut Dysbiosis}

B. fragilis was initially implicated as a causative agent in lamb diarrheal diseases in the 1980s [18]. Further studies have implicated ETBF in diarrheal disease in humans and other animal species [5, 19]. ETBF infections are now known to cause inflammatory diarrheal illnesses in children and adults [3]. The implication that ETBF is a cause of inflammatory disease is further supported by experiments in animal models which have shown that ETBF infection in mice cause acute symptomatic colitis and persistent inflammation of the colon while NTBF colonized mice exhibited histopathological normality [20]. The ability of ETBF to cause a long lasting inflammatory response in animal models contributes to its potential role as a causative agent in colon cancer. Murine studies utilizing APC/Min mice show that ETBF gavage results in Stat 3 and $\mathrm{T}_{\mathrm{H}}-17$ induced colitis which leads to the development of colon tumors in these mice $[21,22]$. Studies conducted in human colon cancer populations have shown an increased rate of detection of the bft gene in B. fragilis isolates of stool samples from patients with colorectal cancer when compared to control populations [23]. More recently, an examination of the mucosa isolated from tumor samples of colorectal cancer patients show higher levels of $b f t$ in the colon tumor mucosa compared to paired normal tissues [4]. The ability to properly isolate and characterize $B$. fragilis strains in clinical samples is important in further understanding and elucidating the important interactions between the host gut and its microbiome.

\section{METHODS OF ETBF DETECTION}

Currently, simple methods to detect and characterize ETBF colonization or infection in clinical laboratories do not exist. Detection is done through a combination of bacterial isolation and bft gene detection or in-vitro evaluation of BFT biological activity.

\section{Basic Microbiologic Approaches to Isolating B. fragilis Strains}

There are a variety of basic microbiologic techniques used to isolate single strains of $B$. fragilis from a variety of different samples. B. fragilis is an obligate anaerobe, therefore, it is important to note that care should be taken to decrease the amount of time collected specimens are exposed to the air. Use of anaerobic jars and transport media will help to increase the specimen viability [7].

\section{Isolation From Stool}

Stool samples can be collected in two ways: rectal swabs or bulk stool collection. Rectal swabs are streaked on selective media plates and single colonies are isolated and grown separately to test for B. fragilis [18]. Bulk stool collection is more effective in characterizing $B$. fragilis as there is a larger amount of material available for use and the samples can be stored at $-80^{\circ} \mathrm{C}$ for long periods of time without affecting $B$. fragilis isolation ability [24]. Samples collected from bulk stool are then plated on Bacteroides Bile Esculin (BBE) selective media, grown anaerobically at $37^{\circ} \mathrm{C}$ to selectively grow strains from the $B$. fragilis group. B. fragilis grown on BBE media will present as raised grey colonies that have hydrolyzed esculin turning the plate black [25]. Furthermore, isolation of $B$. fragilis can be enhanced by anaerobically growing a portion of the stool sample in a non-selective broth media such as Brain Heart Infusion (BHI) prior to plating [24].

\section{Isolation From Blood or Tissue}

Tissue samples are also processed for isolation using two methods: broth amplification or tissue homogenization. Broth amplified tissue samples are placed directly in Peptone Yeast Glucose Bile broth (PYGB) following collection. These samples are incubated anaerobically at $37^{\circ} \mathrm{C}$ and plated on Brucella Blood Agar (BRU) and BBE once turbid. Tissue samples that are processed via homogenization are collected in anaerobic transport media, washed in dithiothreitol, and homogenized using a pestle under anaerobic conditions and plated on BRU and BBE following homogenization. Colonies that grow on BRU are then sub-cultured to BBE in order to select for B. fragilis. Addition of this extra growth step on BRU non-selective media can increase the isolation rates of B. fragilis [4]. In addition to BRU, Brucella Laked Blood Agar with Kanamycin and Vancomycin (LKV) plates have also been used [3]. The strains isolated using these methods are then saved for further down-stream analysis. Isolation of single colonies using these basic microbiological methods are necessary if characterization of individual $B$. fragilis isolates is required. Rapid testing for the presence or absence of $B$. fragilis can be conducted using fecal DNA extraction techniques if strain isolation is not necessary. 


\section{BFT Toxin Assay}

Early on, BFT biological activity was assessed using lamb ileal loop and reversible ileal tie adult rabbit diarrhea (RITARD) assays $[18,26]$. These expensive and labor-intensive methods required the injection of isolated strains into sutured intestinal loops to measure subsequent fluid accumulation as a result of toxin response. In-vitro detection methods were then developed using cell culture based HT29/C1 cell assay. This cell assay detects as low as 0.5 pM BFT with 100\% specificity when compared to lamb ileal loop assay by microscopically observing the cellular morphological changes caused by BFT [27, 28]. For more than two decades this cell assay has played an important role in assessing $B$. fragilis isolated from clinical samples in order to diagnose ETBF infection and characterize the relative amount of toxin produced by ETBF strains. In the laboratory setting, this assay has been widely used to elucidate the mechanism through which BFT effects intestinal cells [16, 17, 29, 30]. The limitation of this cell assay is the requirement of the cell culture and in most cases, overnight growth of bacterial isolates.

Table 1. PCR primer sets used to characterize $B$. fragilis and BFT gene isotypes.

\begin{tabular}{|c|c|c|c|c|c|}
\hline Primer name & Primer sequence $\left(5^{\prime} \rightarrow 3^{\prime}\right)$ & Reference strain / gene access & $\begin{array}{c}\text { Bacterial } \\
\text { target }\end{array}$ & Gene & Reference(s) \\
\hline Leu-3 & CACTTGACTGTTGTAGATAAAGC & \multirow{3}{*}{$\begin{array}{c}\text { CR626927.1, AP006841.1, } \\
\text { NC_016776.1 }\end{array}$} & \multirow{3}{*}{ B. fragilis } & \multirow{3}{*}{$l e u \mathrm{~B}$} & \multirow{3}{*}{ [37] } \\
\hline Leu-4 & CATCTTCATTGCAGCATTATCC & & & & \\
\hline Leu-Prb & TGTGCTTGCTTCCAGTCGTCTATG & & & & \\
\hline Bf904F & GGCGGTCTTCCGGGTAAA & \multirow{3}{*}{$\begin{array}{c}\text { GU130198; GU130199; GU130200, } \\
\text { CR626927 }\end{array}$} & \multirow{3}{*}{ B. fragilis } & \multirow{3}{*}{ gyr B } & \multirow{3}{*}[32,38]{} \\
\hline Bf958R & CACACTTCTGCGGGTCTTTGT & & & & \\
\hline Bf923-MGB & FAM-TGGCCGACTGCTC-MGBNFQ & & & & \\
\hline qHS601F & GTTGTGAAAGTTTGCGGCTCA & \multirow{3}{*}{ ATCC25285/CR626927 } & \multirow{3}{*}{ B. fragilis } & \multirow{3}{*}{$\begin{array}{l}16 \mathrm{~S} \\
\text { rRNA }\end{array}$} & \multirow{3}{*}[33,39]{} \\
\hline qBAc725R & CAATCGGAGTTCTTCGTGATATCTA & & & & \\
\hline qHS624MGB & FAM-CGTAAAATTGCAGTTGA-MGB & & & & \\
\hline $\mathrm{F}$ & TCRGGAAGAAAGCTTGCT & \multirow{3}{*}{ ATCC25285/CR626927 } & \multirow{3}{*}{ B. fragilis } & \multirow{3}{*}{$\begin{array}{l}16 \mathrm{~S} \\
\text { rRNA }\end{array}$} & \multirow{3}{*}[31]{$^{\mathrm{a}}$} \\
\hline $\mathrm{R}$ & CATCCTTTACCGGAATCCT & & & & \\
\hline Prob & ACACGTATCCAACCTGCCCTTTACTCG & & & & \\
\hline $\mathrm{bftF}$ & GGG ACA AGG ATT CTA CCA GCT TTA TA & \multirow{3}{*}{$\begin{array}{c}\text { VPI } 13784 \text { (bft-1), } \\
\text { (bft-2) }\end{array}$} & \multirow{3}{*}{ ETBF } & \multirow{3}{*}{$b f t$} & \multirow{3}{*}[36,40]{} \\
\hline bftR & ATT CGG CAA TCT CAT TCA TCA TT & & & & \\
\hline bftProb & CGC AAT GGC GAA TCC ATC AGC TAC A & & & & \\
\hline bft-1F & GGG ATG TCC TGG TTC A & \multirow{3}{*}{ AB026625 } & \multirow{3}{*}{ ETBF } & \multirow{3}{*}{$b f t-1$} & \multirow{9}{*}[36,40]{} \\
\hline bft-1R & AAT TAT CCG TAT GCT CAG CG & & & & \\
\hline bft-1Prob & CTT CGG ATT TTR AAG CCA GTG GGA TGT C & & & & \\
\hline bft-2F & CTT AGG CAT ATC TTG GCT TG & \multirow{3}{*}{ AB026626 } & \multirow{3}{*}{ ETBF } & \multirow{3}{*}{$b f t-2$} & \\
\hline bft-2R & GCG ATT CTA TAC ATG TTC TC & & & & \\
\hline bft-2Prob & CTT CGG ATT TTR AAG CCA GTG GGA TGT C & & & & \\
\hline bft-3F & TTT GGG CAT ATC TTG GCT CA & \multirow{3}{*}{ AB026624 } & \multirow{3}{*}{ ETBF } & \multirow{3}{*}{$b f t-3$} & \\
\hline bft-3R & ATC ATC CGC ATG GTT AGC A & & & & \\
\hline bft-3Prob & CTT CGG ATT TTR AAG CCA GTG GGA TGT C & & & & \\
\hline
\end{tabular}

${ }^{\mathrm{a}} \mathrm{PCR}$ primers/probes to detect other members in $B$. fragilis group were also described in this report.

\section{PCR Based Detection}

\section{Detection of B. fragilis}

Polymerase chain reactions (PCR) are an important method in B. fragilis and BFT detection due to its quick turnaround time (hours) as well as independence from strain viability and storage conditions. PCR based detection allows for flexibility in collection methods used in gathering samples. A large number of PCR methods for the detection of B. fragilis have been characterized and previously reported at length in a review by C.L. Sears in 2009, including conventional, nested, and multiplex PCR [14]. Multiplex PCR reactions are more specific with the ability to differentiate between species of the $B$. fragilis group present from a series of four multiplex PCR reactions [6]. More recent real-time PCR (RT-PCR) protocols targeting 16S rRNA for detection of B. fragilis group species with lower detection limits were also reported [31]. PCR based on genes specific to $B$. fragilis have also been reported to achieve higher specificity of detection. Beta-isopropylmalate dehydrogenase (leuB), a gene used in leucine biosynthesis, and the 
B-subunit of DNA gyrase $(g y \mathrm{~B})$ are both genes that have been used as PCR targets to detect B. fragilis [32 - 34]. These reports compared RT-PCR protocols with conventional PCR and RT-PCR developed based on a set of primers and probes that amplified 16S rRNA regions conserved among B. fragilis group species and concluded that RT-PCRs targeting single-copied genes show better specificity. These PCR protocols are capable to rapidly characterize $B$. fragilis group species and have become an important tool for discerning clinical infections and identification of relevant bacterium.

\section{Detection of Enterotoxigenic B. fragilis (ETBF)}

Conventional PCR assays detecting BFT have been successful in determining the specific isotype of toxin present in culture by attempting to identify the presence of $b f t$ gene. Detection of the $b f t$ gene without characterization of the toxin isotype has been described using boiled bacterial DNA obtained from cultured isolates [3]. Multiplex PCR assays able to identify the toxin subtype present in boiled bacterial DNA samples have also been developed [35]. These assays are able to quickly confirm the identity of relevant clinical strains but are only useful for conventionally isolated bacteria.

\section{Real Time PCR Detection of B. fragilis}

Detection methods using real time or quantitative PCR are especially useful to determine the presence of $B$. fragilis in mixed clinical samples. A series of relevant real-time PCR primer sets for the detection of $B$. fragilis and BFT isotypes are shown in Table 1. Detection of the $b f t$ gene in DNA extracted directly from stool samples of patients with diarrhea was used in development of a quantitative PCR assay. The developed assay was capable of determining the $b f t$ gene isotype as well [36]. Development of q-PCR assays capable of directly testing DNA isolated from patient stool is extremely useful in the detection of relevant clinical infections. Other experiments have shown that incubation of stool samples in PYBG broth assists in increasing the sensitivity of detection [24]. A study comparing conventional and realtime PCR detection of $B$. fragilis indicated that conventional PCR reactions were less sensitive, but the overall turnaround time for detection and analysis was similar [37].

\section{FUTURE PERSPECTIVES}

Nearly three decades have passed since enterotoxigenic B. fragilis was first identified as a pathogen in diarrheal diseases of both human and animals. More recent studies associating ETBF with colorectal cancer highlight the importance of this bacterium in clinical and public health settings [4].

Traditional bacterial culture method will remain essential for isolation and characterization of $B$. fragilis and ETBF. However, current efforts to simplify anaerobic bacterial culture processes using antioxidants can potentially help with decreasing labor time and sensitivity associated with anaerobic culture processing [41].

Improving detection methods is especially useful for the clinical diagnostic laboratory. Development of TaqMan RT-PCR based high-throughput direct detection of ETBF from stool and other clinical samples will minimize labor and time involved while allowing for automated interpretation of results with high sensitivity and specificity. Recent commercialized digital PCR (dPCR) technology may become an important tool in detecting ETBF in fecal and environmental samples as it is capable of offering quantifiable and more accurate detection of ETBF directly in the gut microbiome. Recently, a new culture based system termed culturomics has been described [42]. By using various antibiotics and inhibitors this method allows for the selective growth of bacterial species present in low quantities in gut populations. When it is combined with matrix-assisted laser desorption ionization time-of-flight (MALDI-TOF) or 16S rRNA sequencing, this method may provide a way to overcome the drawback of the current metagenomics approach in studying minor populations of the gut microbiome. In the future, this combined system may replace current phenotypic methods in clinical laboratories allowing for rapid identification of microbial species in stool and other samples. ELISAs are very useful tools in being able to detect the presence of pathogens in patient samples. Measurements of human serum samples show that individuals infected with ETBF had increased levels of both $\operatorname{IgA}$ and IgG against BFT when compared to controls [3]. A sensitive and specific ELISA assays needs to be optimized and applied to clinical studies as ELISAs will play a crucial role in quick diagnostic tests to characterize ETBF strains in patient samples and allow for a longitudinal investigation of ETBF infections. Current work is being done by this lab to develop a BFT ELISA in order to ultimately develop a rapid test capable of identifying BFT responses in the clinical laboratory.

Within the past two decades there has been tremendous advancements in molecular biology techniques capable of not only detecting clinically relevant information regarding specific pathogens but also in assisting with the determination of specific host-pathogen interactions at a genetic level. The tools outlined in this review are crucial in 
assisting in expanding our understanding of these pathogens and their disease relationships. Currently, steps are being taken to increase the sensitivity of many of these detection methods. We hope that further advances in the implementation of molecular biology techniques will allow for a more comprehensive understanding of the role of enterotoxigenic $B$. fragilis in the human gut microbiome.

\section{CONCLUSION}

There has been abundant research conducted in an attempt to characterize the role of enterotoxigenic $B$. fragilis in human gut dysbiosis and clinical pathologies. The ability to effectively isolate and characterize these strains from clinical or laboratory specimens is essential for further investigating the important impact these bacterium have on human colon health. In this review we provided a brief overview of the various gross microbiologic techniques used to isolate bacterial colonies from various sample types. Additionally, molecular biology techniques currently available to properly characterize these strains as well as assays to assess biological activity are reviewed. While there are well established techniques suitable for the isolation and characterization of ETBF the implementation of high throughput screening methodologies and immunoassays currently being developed will assist researchers to characterize these species in a more sensitive manner.

\section{CONFLICT OF INTEREST}

The authors confirm that this article content has no conflict of interest.

\section{ACKNOWLEDGEMENTS}

Declared none.

\section{REFERENCES}

[1] Polk BF, Kasper DL. Bacteroides fragilis subspecies in clinical isolates. Ann Intern Med 1977; 86(5): 569-71. [http://dx.doi.org/10.7326/0003-4819-86-5-569] [PMID: 322563]

[2] Goldstein EJ. Anaerobic bacteremia. Clin Infect Dis 1996; 23(Suppl. 1): S97-S101. [http://dx.doi.org/10.1093/clinids/23.Supplement_1.S97] [PMID: 8953114]

[3] Sears CL, Islam S, Saha A, et al. Association of enterotoxigenic Bacteroides fragilis infection with inflammatory diarrhea. Clin Infect Dis 2008; 47(6): 797-803.

[http://dx.doi.org/10.1086/591130] [PMID: 18680416]

[4] Boleij A, Hechenbleikner EM, Goodwin AC, et al. The Bacteroides fragilis toxin gene is prevalent in the colon mucosa of colorectal cancer patients. Clin Infect Dis 2015; 60(2): 208-15.

[http://dx.doi.org/10.1093/cid/ciu787] [PMID: 25305284]

[5] Sack RB, Myers LL, Almeido-Hill J, et al. Enterotoxigenic Bacteroides fragilis: epidemiologic studies of its role as a human diarrhoeal pathogen. J Diarrhoeal Dis Res 1992; 10(1): 4-9. [PMID: 1619243]

[6] Liu C, Song Y, McTeague M, Vu AW, Wexler H, Finegold SM. Rapid identification of the species of the Bacteroides fragilis group by multiplex PCR assays using group- and species-specific primers. FEMS Microbiol Lett 2003; 222(1): 9-16.

[http://dx.doi.org/10.1016/S0378-1097(03)00296-9] [PMID: 12757940]

[7] Wexler HM. Bacteroides: the good, the bad, and the nitty-gritty. Clin Microbiol Rev 2007; 20(4): $593-621$. [http://dx.doi.org/10.1128/CMR.00008-07] [PMID: 17934076]

[8] Salyers AA. Bacteroides of the human lower intestinal tract. Annu Rev Microbiol 1984; 38: $293-313$. [http://dx.doi.org/10.1146/annurev.mi.38.100184.001453] [PMID: 6388494]

[9] Wick EC, Sears CL. Bacteroides spp. and diarrhea. Curr Opin Infect Dis 2010; 23(5): 470-4. [http://dx.doi.org/10.1097/QCO.0b013e32833da1eb] [PMID: 20697287]

[10] Troy EB, Kasper DL. Beneficial effects of Bacteroides fragilis polysaccharides on the immune system. Front Biosci (Landmark Ed) 2010; 15: 25-34. [http://dx.doi.org/10.2741/3603] [PMID: 20036803]

[11] Franco AA, Cheng RK, Chung GT, Wu S, Oh HB, Sears CL. Molecular evolution of the pathogenicity island of enterotoxigenic Bacteroides fragilis strains. J Bacteriol 1999; 181(21): 6623-33. [PMID: 10542162]

[12] Sears CL. The toxins of Bacteroides fragilis. Toxicon 2001; 39(11): 1737-46. [http://dx.doi.org/10.1016/S0041-0101(01)00160-X] [PMID: 11595636]

[13] Wu S, Dreyfus LA, Tzianabos AO, Hayashi C, Sears CL. Diversity of the metalloprotease toxin produced by enterotoxigenic Bacteroides fragilis. Infect Immun 2002; 70(5): 2463-71. 
[http://dx.doi.org/10.1128/IAI.70.5.2463-2471.2002] [PMID: 11953383]

[14] Sears CL. Enterotoxigenic Bacteroides fragilis: a rogue among symbiotes. Clin Microbiol Rev 2009; 22(2): 349-69. [Table of Contents.]. [http://dx.doi.org/10.1128/CMR.00053-08] [PMID: 19366918]

[15] Wu S, Shin J, Zhang G, Cohen M, Franco A, Sears CL. The Bacteroides fragilis toxin binds to a specific intestinal epithelial cell receptor. Infect Immun 2006; 74(9): 5382-90. [http://dx.doi.org/10.1128/IAI.00060-06] [PMID: 16926433]

[16] Wu S, Lim KC, Huang J, Saidi RF, Sears CL. Bacteroides fragilis enterotoxin cleaves the zonula adherens protein, E-cadherin. Proc Natl Acad Sci USA 1998; 95(25): 14979-84.

[http://dx.doi.org/10.1073/pnas.95.25.14979] [PMID: 9844001]

[17] Wu S, Powell J, Mathioudakis N, Kane S, Fernandez E, Sears CL. Bacteroides fragilis enterotoxin induces intestinal epithelial cell secretion of interleukin-8 through mitogen-activated protein kinases and a tyrosine kinase-regulated nuclear factor-kappaB pathway. Infect Immun 2004; 72(10): 5832-9.

[http://dx.doi.org/10.1128/IAI.72.10.5832-5839.2004] [PMID: 15385484]

[18] Myers LL, Firehammer BD, Shoop DS, Border MM. Bacteroides fragilis: a possible cause of acute diarrheal disease in newborn lambs. Infect Immun 1984; 44(2): 241-4. [PMID: 6538870]

[19] Myers LL, Shoop DS, Firehammer BD, Border MM. Association of enterotoxigenic Bacteroides fragilis with diarrheal disease in calves. J Infect Dis 1985; 152(6): 1344-7. [http://dx.doi.org/10.1093/infdis/152.6.1344] [PMID: 3905990]

[20] Rhee KJ, Wu S, Wu X, et al. Induction of persistent colitis by a human commensal, enterotoxigenic Bacteroides fragilis, in wild-type C57BL/6 mice. Infect Immun 2009; 77(4): 1708-18. [http://dx.doi.org/10.1128/IAI.00814-08] [PMID: 19188353]

[21] Wu S, Rhee KJ, Albesiano E, et al. A human colonic commensal promotes colon tumorigenesis via activation of $\mathrm{T}$ helper type $17 \mathrm{~T}$ cell responses. Nat Med 2009; 15(9): 1016-22. [http://dx.doi.org/10.1038/nm.2015] [PMID: 19701202]

[22] Wick EC, Rabizadeh S, Albesiano E, et al. Stat3 activation in murine colitis induced by enterotoxigenic Bacteroides fragilis. Inflamm Bowel Dis 2014; 20(5): 821-34. [http://dx.doi.org/10.1097/MIB.0000000000000019] [PMID: 24704822]

[23] Toprak NU, Yagci A, Gulluoglu BM, et al. A possible role of Bacteroides fragilis enterotoxin in the aetiology of colorectal cancer. Clin Microbiol Infect 2006; 12(8): 782-6.

[http://dx.doi.org/10.1111/j.1469-0691.2006.01494.x] [PMID: 16842574]

[24] Chen LA, Van Meerbeke S, Albesiano E, et al. Fecal detection of enterotoxigenic Bacteroides fragilis. Eur J Clin Microbiol Infect Dis 2015; 34(9): 1871-7. [http://dx.doi.org/10.1007/s10096-015-2425-7] [PMID: 26173688]

[25] Ramamurthy D, Pazhani GP, Sarkar A, et al. Case-control study on the role of enterotoxigenic Bacteroides fragilis as a cause of diarrhea among children in Kolkata, India. PLoS One 2013; 8(4): e60622.

[http://dx.doi.org/10.1371/journal.pone.0060622] [PMID: 23577134]

[26] Myers LL, Shoop DS, Stackhouse LL, et al. Isolation of enterotoxigenic Bacteroides fragilis from humans with diarrhea. J Clin Microbiol 1987; 25(12): 2330-3

[PMID: 3429625]

[27] Weikel CS, Grieco FD, Reuben J, Myers LL, Sack RB. Human colonic epithelial cells, HT29/C1, treated with crude Bacteroides fragilis enterotoxin dramatically alter their morphology. Infect Immun 1992; 60(2): 321-7. [PMID: 1730463]

[28] Saidi RF, Sears CL. Bacteroides fragilis toxin rapidly intoxicates human intestinal epithelial cells (HT29/C1) in vitro. Infect Immun 1996; 64(12): 5029-34.

[PMID: 8945542]

[29] Wu S, Morin PJ, Maouyo D, Sears CL. Bacteroides fragilis enterotoxin induces c-Myc expression and cellular proliferation. Gastroenterology 2003; 124(2): 392-400. [http://dx.doi.org/10.1053/gast.2003.50047] [PMID: 12557145]

[30] Mundy LM, Sears CL. Detection of toxin production by Bacteroides fragilis: assay development and screening of extraintestinal clinical isolates. Clin Infect Dis 1996; 23(2): 269-76. [http://dx.doi.org/10.1093/clinids/23.2.269] [PMID: 8842262]

[31] Tong J, Liu C, Summanen P, Xu H, Finegold SM. Application of quantitative real-time PCR for rapid identification of Bacteroides fragilis group and related organisms in human wound samples. Anaerobe 2011; 17(2): 64-8. [http://dx.doi.org/10.1016/j.anaerobe.2011.03.004] [PMID: 21439390]

[32] Lee CS, Lee J. Evaluation of new gyrB-based real-time PCR system for the detection of $B$. fragilis as an indicator of human-specific fecal contamination. J Microbiol Methods 2010; 82(3): 311-8. [http://dx.doi.org/10.1016/j.mimet.2010.07.012] [PMID: 20643165] 
[33] Lee CS, Marion JW, Lee J. A novel genetic marker for the rapid detection of Bacteroides fragilis in recreational water as a human-specific faecal indicator. J Water Health 2011; 9(2): 253-64. [http://dx.doi.org/10.2166/wh.2011.120] [PMID: 21942191]

[34] Miki T, Kuwahara T, Nakayama H, et al. Simultaneous detection of Bacteroides fragilis group species by leuB-directed PCR. J Med Invest 2005; 52(1-2): 101-8. [http://dx.doi.org/10.2152/jmi.52.101] [PMID: 15751280]

[35] Avila-Campos MJ, Liu C, Song Y, Rowlinson MC, Finegold SM. Determination of bft gene subtypes in Bacteroides fragilis clinical isolates. J Clin Microbiol 2007; 45(4): 1336-8. [http://dx.doi.org/10.1128/JCM.02108-06] [PMID: 17301286]

[36] Merino VR, Nakano V, Liu C, Song Y, Finegold SM, Avila-Campos MJ. Quantitative detection of enterotoxigenic Bacteroides fragilis subtypes isolated from children with and without diarrhea. J Clin Microbiol 2011; 49(1): 416-8. [http://dx.doi.org/10.1128/JCM.01556-10] [PMID: 20980581]

[37] Papaparaskevas J, Mela V, Houhoula DP, Pantazatou A, Petrikkos GL, Tsakris A. Comparative evaluation of conventional and real-time PCR assays for detecting Bacteroides fragilis in clinical samples. J Clin Microbiol 2013; 51(5): 1593-5. [http://dx.doi.org/10.1128/JCM.00449-13] [PMID: 23447634]

[38] Ji D, Huang IH, Lai CC, et al. Prevalence and characterization of enterotoxigenic Bacteroides fragilis and toxigenic Clostridium difficile in a Taipei emergency department. J Microbiol Immunol Infect 2014; S1684-1182(14)00255-2. [PMID: 25648668]

[39] Okabe S, Shimazu Y. Persistence of host-specific Bacteroides-Prevotella 16S rRNA genetic markers in environmental waters: effects of temperature and salinity. Appl Microbiol Biotechnol 2007; 76(4): 935-44. [http://dx.doi.org/10.1007/s00253-007-1048-z] [PMID: 17598108]

[40] Franco AA, Mundy LM, Trucksis M, Wu S, Kaper JB, Sears CL. Cloning and characterization of the Bacteroides fragilis metalloprotease toxin gene. Infect Immun 1997; 65(3): 1007-13. [PMID: 9038310]

[41] La Scola B, Khelaifia S, Lagier JC, Raoult D. Aerobic culture of anaerobic bacteria using antioxidants: a preliminary report. Eur J Clin Microbiol Infect Dis 2014; 33(10): 1781-3 [http://dx.doi.org/10.1007/s10096-014-2137-4] [PMID: 24820294]

[42] Lagier JC, Armougom F, Million M, et al. Microbial culturomics: paradigm shift in the human gut microbiome study. Clin Microbiol Infect 2012; 18(12): 1185-93. [http://dx.doi.org/10.1111/1469-0691.12023] [PMID: 23033984]

Received: July 13, $2015 \quad$ Revised: October 20, 2015
Accepted: October 22, 2015

(C) Fathi and Wu; Licensee Bentham Open

This is an open access article licensed under the terms of the Creative Commons Attribution-Non-Commercial 4.0 International Public License (CC BY-NC 4.0) (https://creativecommons.org/licenses/by-nc/4.0/legalcode), which permits unrestricted, non-commercial use, distribution and reproduction in any medium, provided the work is properly cited. 